Guirao Rubio, Pilar. Técnicas y hábitos de estudio de la asignatura de Historia en Secundaria y Bachillerato. GeoGraphos. [En línea]. Alicante: Grupo Interdisciplinario de Estudios Críticos y de América Latina (GIECRYAL) de la Universidad de Alicante, 20 de febrero de 2013, vol. 4, no 42, p. 238-263. [ISSN: 2173-1276].

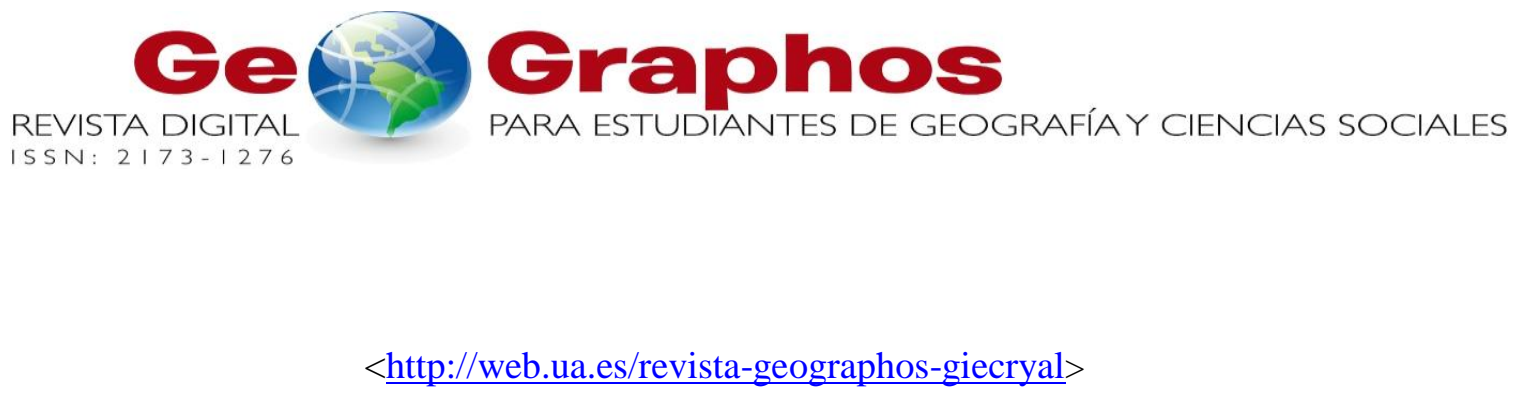

Vol. 4. $\mathrm{N}^{\mathrm{o}} 42$

Año 2013

\title{
TÉCNICAS Y HÁBITOS DE ESTUDIO DE LA ASIGNATURA DE HISTORIA EN SECUNDARIA Y BACHILLERATO
}

\author{
Pilar Guirao Rubio \\ Programa de Doctorado en Investigación Educativa \\ Facultad de Educación. Universidad de Alicante. Alicante (España) \\ Correo electrónico: pilarguiraorubio13@gmail.com
}

Recibido: 13 de diciembre de 2012. Aceptado: 20 de febrero de 2013

\section{RESUMEN}

El presente estudio pretende analizar los hábitos y técnicas para el estudio de la asignatura de historia en los niveles de Secundaria y Bachillerato. Para ello, se han realizado cuestionarios a alumnos de los diferentes cursos a estudiar y se han analizado los resultados, llegando a la conclusión de que el uso de métodos y hábitos que faciliten la asimilación de conocimientos históricos va en aumento conforme los alumnos van ascendiendo de nivel, de modo que los alumnos de $1^{\circ}$ de la ESO mantienen una línea de aprendizaje heredera de su etapa en el colegio, mientras los estudiantes de $4^{\circ}$ de la ESO y sobre todo de $2^{\circ}$ de Bachillerato presentan una metodología de estudio más marcada que les otorga una mayor autonomía en su proceso asimilación de la información histórica.

Palabras clave: Métodos de estudio, Hábitos de estudio, Conocimiento histórico, Secundaria, Bachillerato. 


\title{
TECHNIQUES AND HABITS FOR THE SUBJECT OF HISTORY IN SECONDARY AND A LEVEL
}

\begin{abstract}
This study tries to analise the habits and techiques for the subject of History in Secondary and A level. For it, surveys have been made to pupils from de different year and the results have been analised. The conclusion is habits and techniques are more used when level is higher, so that the pupils of Secondary support a line of learning inheritor of his stage in the college, whereas the pupils of A level present a methodology of study more marked that grants a major autonomy to them in his process assimilation of historical information.
\end{abstract}

Key words: Study's habits, Study's techniques, Historical knowledge, Secondary, A level.

\section{TÉCNICAS E HÁBITOS DE ESTUDO DA DISCIPLINA DE HISTÓRIA NO ENSINO MÉDIO E ENSINO MÉDIO}

\section{RESUMO}

Este estudo pretende analisar os hábitos e técnicas para o estudo da disciplina de história nos níveis secundários e colegial. Para este efeito, questionários foram alunos de diferentes cursos para estudar e os resultados foram analisados, chegando à conclusão de que o uso de métodos e hábitos que facilitam a assimilação de conhecimento histórico está a aumentar como alunos são crescente nível, então 1 de ESO alunos mantêm uma herdeira de aprendizagem de sua linha de estágio na faculdade. Enquanto os alunos do $4^{\circ}$ ESO e em todos do $2^{\circ}$ ensino médio apresentado uma metodologia de estudo mais pronunciado que concede-lhes uma maior autonomia na sua assimilação do processo de informação histórica.

Palabras-chave: Técnicas de estudo, Hábitos de estudo, Conhecimento histórico, Nivei secundario, Ensino médio.

\section{INTRODUCCIÓN}

Es el objeto del presente escrito analizar una problemática cuanto menos clave en el proceso de enseñanza-aprendizaje (a partir de ahora E/A) en general, pero sobre todo, en el caso que nos ocupa, aplicado a la asignatura de Historia, tanto en la Enseñanza Secundaria como en Bachillerato. Se trata pues, de la carencia o precariedad de técnicas y hábitos de estudio eficaces que hagan del aprendizaje de nuestra materia una adquisición de conocimientos perdurables y firmes en la estructura cognitiva del alumnado receptor.

Desde hace ya bastantes años, debido al fracaso escolar con que, desgraciadamente, contamos en nuestras aulas, el fomento de estrategias y hábitos de estudio ha sido una temática fruto de estudio, que ha propiciado la publicación de numerosa bibliografía, así 
como la realización de cursos sobre el uso de métodos eficaces a la hora de estudiar. Sin embargo, la aplicación práctica de todos los recursos que trataremos a lo largo del escrito no es tan asidua como así quisiéramos.

Entendemos como "técnica", el "conjunto de procedimientos y recursos de que se sirve una ciencia o un arte", así como la "habilidad para ejecutar cualquier cosa, o para conseguir algo" (RAE), incluso "el camino para llegar a algo" o "la manera ordenada de proceder para alcanzar unas finalidades previstas"1. Por tanto, cuando consideramos que el alumno debe disponer de técnicas propias que aplicar al estudio de la historia no nos referimos más que a la importancia de que el estudiante encuentre los medios apropiados para conseguir que todo aquello que aprende en el aula como receptor de conocimientos quede consolidado en su estructura cognitiva, consiguiendo así un aprendizaje significativo. Cuando hacemos referencia a este tipo de aprendizaje nos referimos a aquel en que el alumno es capaz de relacionar los nuevos conocimientos con los que ya posee, elaborando un conocimiento global entre lo que ya sabía y lo recién aprehendido ${ }^{2}$.Su impulsor afirma que de tener que reducir toda la psicología educativa a un solo principio, consideraría que el factor más importante que influye en el aprendizaje es lo que el alumno ya sabe, por ello se debe averiguar para actuar en consecuencia (Ausubel, 1978). El punto clave para conseguir tal fin lo hayamos en la comprensión, pues si un alumno no entiende aquello que se le explica, difícilmente va a conectarlo con informaciones o experiencias ya asimiladas. El alumno se convertiría así en el responsable de su aprendizaje, jugando el docente el rol de guía, pero no sería el garante del éxito o fracaso del alumnado, como así considera la rama más tradicional en la psicología de la educación. Consideramos, por tanto, que un estudiante ha de comprender aquello que estudia, iniciando su camino más allá de la memorización y es por ello que pensamos es tan importante el uso de recursos o estrategias que así lo hagan posible.

Muchas son las personas, y por consiguiente los alumnos, que consideran que la historia es una materia donde únicamente cobra importancia la capacidad memorística de quien la estudia, pues se trata de un conjunto de hechos y fechas. Esto, frente al aprendizaje significativo expuesto anteriormente, se engloba en un tipo de estudio mecanicista, donde la nueva información es incorporada de forma automática, sin relacionarse con lo que ya se sabe y en muchos de los casos, sin apenas comprender aquello que se memoriza. Es lo que se conoce como memoria a corto plazo.

Sin embargo, y más allá de un conjunto de hechos y fechas, la historia es el estudio de los procesos, procesos que si no son comprendidos no tardarán en desaparecer de nuestro recuerdo. Por todo ello se ha de desbancar esta idea de "historia memorística" y se ha de afrontar el estudio de la asignatura atendiendo a diferentes técnicas y métodos, adecuados a las preferencias y necesidades de los propios estudiantes, que además, han de incorporar unos hábitos sencillos pero constantes que facilitarán en gran medida la adquisición significativa de los conocimientos históricos. Consideramos, de este modo, que si el estudio de la historia se afrontara de la forma adecuada, con los recursos idóneos para tal fin, se restaría dificultad a su aprendizaje y por tanto los resultados serían mejores, así como la visión que de la asignatura tienen los alumnos, pues en su mayoría la consideran aburrida y monótona.

\footnotetext{
${ }^{1}$ SEBASTIÁ, R. Investigación e innovación en didáctica de las Ciencias Sociales: Historia.

${ }^{2}$ LARA, J. y LARA, L. Recursos para un aprendizaje significativo.
} 
Pensamos, con ello, que independientemente de las aptitudes intelectuales de cada cual, el éxito o fracaso académico depende en gran medida de la aplicación de una metodología de estudio adecuada, pues estudiar sin método es sinónimo de "no saber estudiar” y por tanto el desfase entre el trabajo y el rendimiento será abismal.

La falta de aplicación práctica de estrategias de estudio es una problemática que comienza a gestarse en los primeros momentos de la Enseñanza Secundaria. Durante la etapa primaria, el aprendizaje de los niños está mucho más guiado, cobrando el maestro el papel más importante en la educación escolar. El alumno se limita a hacer las tareas diarias y cuando ya en $1^{\circ}$ de ESO debe adoptar una responsabilidad (programar sus actividades, sus tareas, sus horas de estudio), le es difícil afrontar y aprovechar ventajosamente la autonomía de la que dispone, pues no está acostumbrado y necesita un periodo de adaptación, que en la mayoría de los casos, no concluye con el uso de una metodología de trabajo efectiva.

Es, por tanto, indispensable que el alumno, una vez llegado a este punto de su etapa académica, desarrolle sus propios recursos para el estudio, establezca sus objetivos y se convierta en guía de su propio aprendizaje. Bien es cierto que la labor del docente es fundamental para facilitar esta ardua tarea, sobre todo a través de un ambiente de aula apto o una buena metodología, pero depende del propio alumno consolidar o no los conocimientos adquiridos en el aula, de ahí, la importancia del estudio. Entendemos como estudio la decisión de metas y la selección de métodos y técnicas para conseguirlas, la solución de problemas, la recogida de información, distinción de opiniones y certezas, la comparación de hecho, etc. La capacidad de estudiar, como bien sabemos, no es algo innato, sino que se trata de un conjunto de técnicas que debemos aprender con la experiencia.

Otra de las cuestiones a tratar serán los hábitos de estudio. El hábito es el "modo especial de proceder o conducirse adquirido por repetición de actos iguales $\mathrm{o}$ semejantes, u originado por tendencias instintivas" (RAE) Esto, aplicado a nuestro ámbito, significa que todo alumno ha de dedicar cada día una parte de su jornada al estudio, pues de nada sirve la adquisición de métodos de aprendizaje si únicamente se usan la noche antes del examen. No es eso lo que pretendemos, pues para lograr nuestro tan ansiado aprendizaje significativo, tanto las técnicas como los hábitos en el estudio van a ser de vital importancia.

Por otro lado, resulta curioso que, a pesar de la relevancia del problema que vamos a tratar, y de lo actual de la cuestión materializada en la competencia básica de "aprender a aprender", no haya a lo largo de toda la escolaridad ni una sola materia que dedique una parte de su temporalización a mostrar al alumnado algunas pequeñas pautas, que le serían de gran utilidad a la hora de organizar la información, distinguir la principal de la secundaria, esquematizar los contenidos y, en definitiva, facilitar la adquisición de los contenidos a través de claves que harían más productivo el tiempo de estudio.

Esta problemática, además, aparece más arraigada en aquellas asignaturas que, como la historia, requieren trabajar con contenidos muy amplios, con datos concretos o con fechas específicas, de modo que consideramos indispensable paliar esta deficiencia de la enseñanza, que constituye un problema real y muy generalizado. 


\section{RECOGIDA DE INFORMACIÓN. CUESTIONARIOS A LOS ALUMNOS.}

Para profundizar de manera exhaustiva en la problemática a analizar, partimos de la realización de una encuesta a alumnos de tres cursos de Enseñanza Secundaria y Bachiller, en los cuales se imparte la asignatura de historia; $1^{\circ}$ de ESO (Ciencias Sociales: Historia), $4^{a}$ de ESO (Historia Contemporánea) y $2^{\circ}$ de Bachillerato (Historia de España) de un instituto concreto situado en la provincia de Alicante.

Se trata de un cuestionario compuesto por 9 preguntas cerradas divididas en cuatro bloques:

1) Sobre los hábitos de estudio (lugar y horarios).

2) Sobre las técnicas de estudio.

3) Sobre el uso de fuentes más allá de las facilitadas en clase (búsqueda de bibliografía).

4) Sobre el propio proceso de adquisición de conocimientos (memorización o comprensión).

Con todas las respuestas obtenidas podremos hacer un análisis de resultados e ir comprobando, según cada curso, la existencia o no de hábitos y estrategias de estudio, permitiéndonos conocer el estado de la cuestión en base a la realidad de un instituto.

Las variables de análisis que vamos a seguir en el estudio de nuestra problemática se corresponden con los aspectos tratados en la encuesta.

1) Estudiaremos en primer lugar los hábitos en el estudio de la historia de nuestros alumnos, sobre todo en lo que respecta al espacio físico y a la planificación y organización horaria del mismo. Hemos considerado clave introducir estas cuestiones en nuestro estudio al tener en cuenta la importancia que tienen a la hora de crear un óptimo ambiente de aprendizaje.

2) Otra de las variables se centra en las técnicas, y particularmente en saber si el alumnado las utiliza o únicamente lee y memoriza directamente del escrito, ya sean apuntes de clase o el libro de texto, dependiendo de los cursos y las preferencias del profesor. Por tanto, otra de las cuestiones va encaminada a descubrir en que porcentaje y con qué frecuencia se recurre a la realización de esquemas, mapas conceptuales, organigramas..., tratando además, las ventajas e inconvenientes que el uso de estas estrategias conlleva.

3) Un tercer objeto de análisis será el subrayado, considerado previamente como uno de los recursos más extendidos a la hora de estudiar historia; ¿Es útil? ¿Suele usarse en el estudio? ¿Qué ventajas tiene para la adquisición de conocimientos? Todo ello iremos aclarando en las siguientes líneas.

4) Otro de los métodos que consideramos muy generalizados es el resumen, de modo que pretendemos saber con nuestra encuesta si este método ya prácticamente tradicional es verdaderamente tan recurrente como pensamos.

5) Teniendo en cuenta la importancia que tiene en el proceso de E/A la búsqueda de información y el indagar en diferentes tipos de fuentes, pretendemos además conocer si los alumnos acuden o no a la búsqueda de bibliografía, de información en internet, a la 
lectura de artículos... más allá del libro de texto o los apuntes proporcionados por el profesor.

6) Por último, analizaremos si todas estas preguntas que el alumno responde según su propia experiencia, corresponden a un tipo de aprendizaje predominantemente mecánico (asentado en la memorización) o si se comprende aquello que se estudia, alcanzando así la significación de lo aprendido.

Se pretende, pues, tratar diferentes aspectos claves para, en primer lugar, conocer cómo son nuestros estudiantes, y a partir de ahí, desarrollar cada una de las variables para concluir proponiendo métodos concretos que pensamos son fundamentales para que los estudiantes alcancen el éxito en sus estudios.

\section{ANÁLISIS DE LOS RESULTADOS OBTENIDOS EN LAS ENCUESTAS}

La primera variable de análisis, recordemos, hacía referencia a los hábitos, centrándose más concretamente en el lugar de estudio de nuestros alumnos. Ante la pregunta:

¿Estudias siempre en el mismo lugar? Obtuvimos los siguientes resultados:

\section{Cuadro 1. Resultados correspondientes a $1^{\circ}$ de ESO. Lugar de estudio}

\begin{tabular}{|c|c|c|}
\hline $1^{\circ}$ ESO & $\begin{array}{c}\text { TOTAL }= \\
135 \text { alumnos }\end{array}$ & $\%$ \\
\hline Nunca & 13 & 9,62 \\
\hline A veces & 33 & 24,4 \\
\hline $\begin{array}{c}\text { A } \\
\text { menudo }\end{array}$ & 42 & 31,11 \\
\hline Siempre & 47 & 34,8 \\
\hline
\end{tabular}

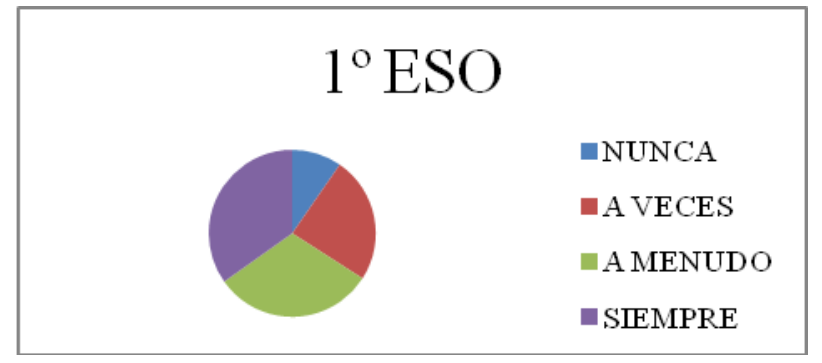

Fuente: Elaboración propia.

Observamos que la mayoría de los alumnos encuestados en $1^{\circ}$ de la ESO (Véase cuadro 1) se debaten entre un "siempre" y un "a menudo", de modo que parece ser un hábito bastante incorporado a la vida estudiantil de los jóvenes. 


\section{Cuadro 2. Resultados correspondientes a $4^{\circ}$ de ESO. Lugar de estudio}

\begin{tabular}{|l|c|c|}
\hline $4^{\circ}$ ESO & $\begin{array}{c}\text { TOTAL }= \\
50 \text { alumnos }\end{array}$ & $\%$ \\
\hline Nunca & 1 & 2 \\
\hline A veces & 3 & 6 \\
\hline $\begin{array}{l}\text { A } \\
\text { menudo }\end{array}$ & 9 & 18 \\
\hline Siempre & 37 & 74 \\
\hline
\end{tabular}

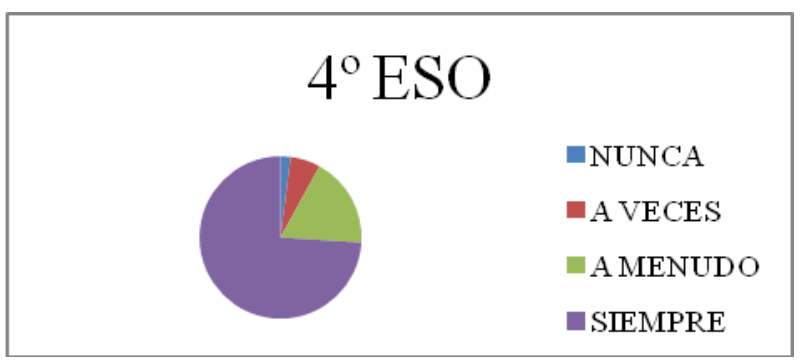

Fuente: Elaboración propia.

Los estudiantes de historia de $4^{\circ}$ de ESO (Véase cuadro 2), por su parte, estudian siempre en un espacio predeterminado y fijo en un $74 \%$ de los casos, cifra muy alta que de nuevo manifiesta que se trata de un eficaz hábito de estudio de cuyas ventajas son conscientes.

\section{Cuadro 3. Resultados correspondientes a $2^{\circ}$ de Bachillerato. Lugar de estudio}

\begin{tabular}{|l|c|c|}
\hline $2^{\circ} \mathrm{BACH}$ & $\begin{array}{c}\text { TOTAL }= \\
96 \text { alumnos }\end{array}$ & $\%$ \\
\hline Nunca & 4 & 4,16 \\
\hline A veces & 11 & 11,45 \\
\hline $\begin{array}{l}\text { A } \\
\text { menudo }\end{array}$ & 29 & 30,20 \\
\hline Siempre & 52 & 54,16 \\
\hline
\end{tabular}

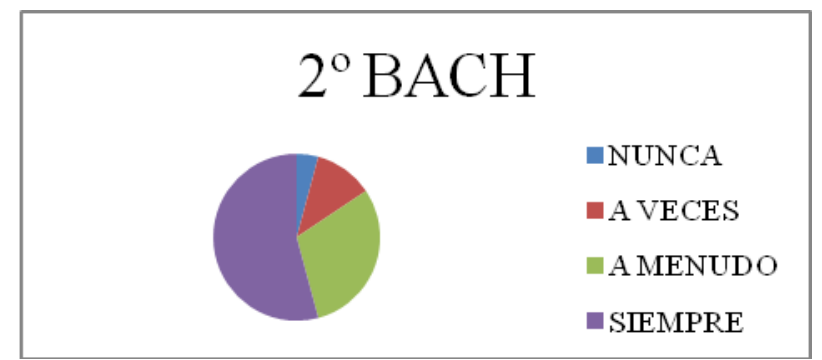

Fuente: Elaboración propia.

La tendencia al estudio en lugares concretos se mantiene en el alumnado de cursos superiores como es el caso de $2^{\circ}$ de Bachillerato (Véase cuadro 3). Nos sorprende, eso sí, que sea menor el porcentaje de alumnos que "siempre" lo hacen con respecto a los estudiantes de $4^{\circ}$ de la ESO. Pensamos que se trata al mayor número de horas libres durante el periodo académico, lo que puede conllevar que el alumno, además de estudiar en su "hábitat" oportuno, lo haga en las dependencias del centro en aquellas horas en las que no tiene clase.

Llegamos a la conclusión, por tanto, de que la ubicación a la hora de desarrollar el aprendizaje no es el problema decisivo que marca el cierto fracaso planteado en el estudio de la historia. Si observamos los datos, nos daremos cuenta que en los tres casos, la mayor parte de los alumnos suele estudiar siempre en el mismo lugar. En este sentido cabe destacar la importancia que tiene en el proceso de E/A el hecho de identificar un lugar único y concreto con el estudio. Tal y como plantean los experimentos Hawthorne (Elton Mayo, 1949), las condiciones ambientales en las que se desarrolla el estudio son indispensables para favorecer, o no, el rendimiento laboral, siendo aplicable, en nuestro caso, al rendimiento escolar. Puede parecer que cualquier sitio es válido para proceder al estudio, sin embargo, los psicólogos consideran que el 
más apropiado es la habitación del estudiante, pues es el lugar donde más cómodos y familiarizados con el espacio nos sentimos. Además del espacio físico propiamente dicho, otros son los factores que intervienen para hacer del mismo un lugar idóneo para el estudio; la iluminación ha de ser preferentemente natural, la temperatura media (demasiado calor produce somnolencia y demasiado frío nerviosismo) y por supuesto hemos de encontrarnos aislados de cualquier tipo de ruido. Por su parte, la postura más apropiada es la que sitúa alumno sentado en una silla, frente a una mesa proporcionada, con la espalda recta, los pies en el suelo y los antebrazos encima de la mesa. De esta manera, al huir de posiciones excesivamente cómodas, los alumnos evitarán situaciones de somnolencia y favorecerán las técnicas de estudio activas (subrayado, esquematización de la información... $)^{3}$.

No podemos obviar un obstáculo claro cuando el alumno se enfrenta al estudio en su habitación, y es que en una sociedad donde las nuevas tecnologías de la información y la comunicación están tan a la orden del día, los adolescentes tienen acceso absoluto a internet y la tentación que suponen las redes sociales y demás distracciones interactivas dificultan sobremanera el proceso de aprendizaje. Por ello varios autores prefieren como lugar de estudio la biblioteca, donde, además, el ambiente de estudio es un estímulo importante.

Pasamos pues a tratar uno de los elementos fundamentales, según consideramos, para alcanzar las metas académicas que cada alumno desee. Nos referimos a la planificación horaria de las sesiones de estudio. La encuesta se refería a este aspecto bajo la siguiente cuestión:

$¿$ Tienes un horario fijo de estudio diario? Analicemos los resultados obtenidos.

\section{Cuadro 4. Resultados correspondientes a $1^{\circ}$ de ESO. Planificación horaria}

\begin{tabular}{|l|c|c|}
\hline $1^{\circ} \mathrm{ESO}$ & $\begin{array}{c}\text { TOTAL } \\
=135\end{array}$ & $\%$ \\
\hline Nunca & 76 & 56,29 \\
\hline A veces & 38 & 28,14 \\
\hline A menudo & 12 & 8,88 \\
\hline Siempre & 9 & 6,66 \\
\hline
\end{tabular}

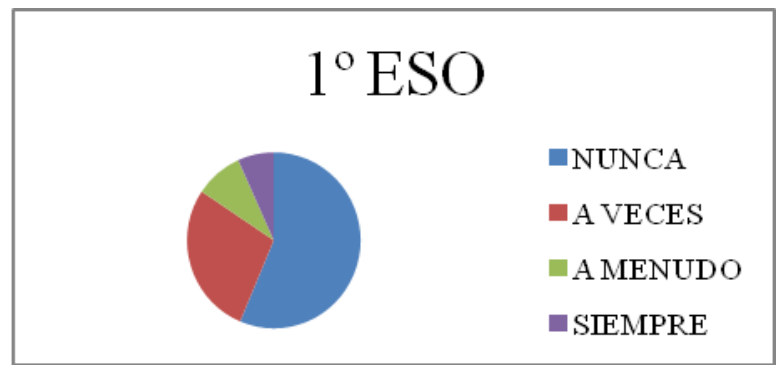

Fuente: Elaboración propia.

A simple vista, podemos identificar que más de la mitad del alumnado que estudia historia en $1^{\circ}$ de ESO (Véase cuadro 4), no tiene un horario fijo de estudio al día, limitándose a trabajar únicamente cuando tiene tareas que entregar en clase al día siguiente. Esta falta de hábitos es, como mencionábamos al principio, heredera de la etapa de educación primaria, donde el maestro era quien establecía todo lo que el alumno debía hacer ${ }^{4}$. Ante esta situación, resulta indispensable que el alumnado vaya adecuando sus hábitos a las nuevas condiciones escolares a las que ha de enfrentarse.

\footnotetext{
${ }^{3}$ SALAS, M. Técnicas de estudio para Secundaria y Universidad.

${ }^{4}$ ROWNTREE, D. Aprende a estudiar. Introducción programada a unas mejores técnicas de estudio.
} 
Esto es, ha de ir progresivamente concienciándose de la necesidad de organizar y planificar su tiempo para cubrir el aprendizaje de todas las asignaturas. El hecho de establecerse un horario de estudio no supone el tener que rechazar el tiempo de ocio, algo que los alumnos, en este caso de 12 años de edad, difícilmente entienden. Claro está que cada día hay que dedicar tiempo a la diversión y el entretenimiento, fundamentales para el desarrollo personal, pero cierto es que si desde esta edad comienzan a dedicar parte de la tarde al estudio, independientemente de que tengan tareas que hacer o no, este hábito acabará beneficiando considerablemente su proceso de E/A.

Cuadro 5. Resultados correspondientes a $4^{\circ}$ de ESO. Planificación horaria

\begin{tabular}{|l|c|c|}
\hline $4^{\circ}$ ESO & $\begin{array}{c}\text { TOTAL } \\
=50\end{array}$ & $\%$ \\
\hline Nunca & 1 & 2 \\
\hline A veces & 7 & 14 \\
\hline A menudo & 18 & 36 \\
\hline Siempre & 24 & 48 \\
\hline
\end{tabular}

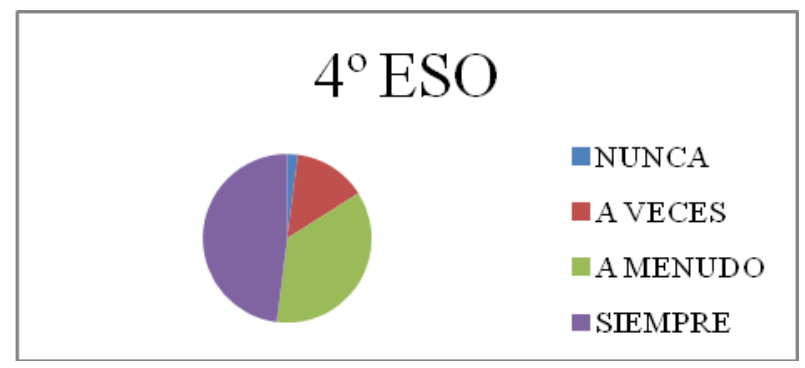

Fuente: Elaboración propia.

Observando los datos que tenemos delante, resulta curiosa la diferencia de resultados entre los alumnos de $4^{\circ}$ de la ESO (Véase cuadro 5) y los de $1^{\circ}$ en cuanto a la planificación horaria de su estudio, pues en este caso vemos que un alto porcentaje de alumnos le dedica todos los días un espacio temporal, aunque sea breve. Según hemos podido comentar con ellos, parece ser que a estas edades son más "maduros" en cierta medida y el temor a fracasar en el ya próximo bachillerato les hace, con algunas excepciones como es lógico, intentar coger el nivel necesario para llegar a $1^{\circ}$ de bachiller sin dificultades.

Cuadro 6. Resultados correspondientes a $2^{\circ}$ de Bachillerato. Planificación horaria

\begin{tabular}{|l|c|c|}
\hline $2^{\circ}$ BACH & $\begin{array}{c}\text { TOTAL } \\
=96\end{array}$ & $\%$ \\
\hline Nunca & 3 & 3,12 \\
\hline A veces & 11 & 11,45 \\
\hline A menudo & 26 & 27,08 \\
\hline Siempre & 56 & 58,3 \\
\hline
\end{tabular}

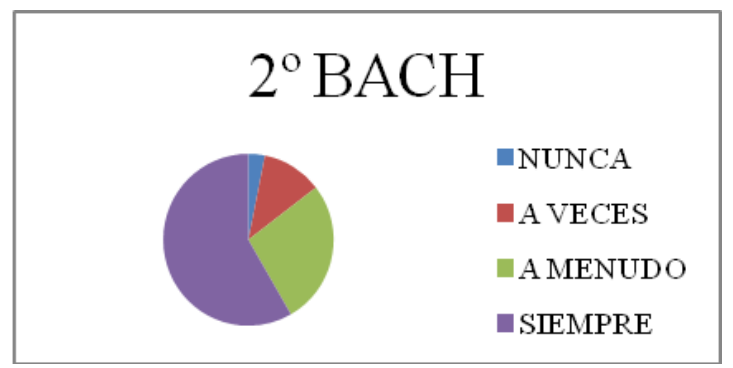

Fuente: Elaboración propia.

Como no es de extrañar, teniendo en cuenta la proximidad de las pruebas PAU, en el último curso del instituto (Véase cuadro 6) más de la mitad de los alumnos tienen establecido un horario en su rutina diaria. 
Podemos observar que, a medida que va aumentando la edad de los estudiantes, va haciéndolo también la conciencia que toman a la hora de organizar su estudio más allá de las horas de permanencia en el centro.

Hemos de justificar esta cuestión argumentando las causas que hacen que la organización y planificación del trabajo sea tan importante en el estudio de la historia. Pues bien, la principal causa no es otra que la relación directa entre hábito de trabajo y rendimiento, de modo que si se convierte en hábito el hecho de estudiar un par de horas al día, la asimilación de conocimientos se hará de forma progresiva y conllevará el recuerdo a largo plazo, al contrario que sucede si lo estudiamos todo el día antes del examen. Aunque parezca una contradicción, dedicar tiempo al estudio aunque no se esté obligado a la realización de tareas concretas, ahorra tiempo y sobre todo energía, pues dosificar el estudio permite repasar la información, lo cual resulta indispensable para alcanzar el aprendizaje significativo que en este trabajo perseguimos sin cesar. Por otro lado, el hecho de que cada día se dedique un tiempo a trabajar, académicamente hablando, hace que con el paso de tiempo no suponga ningún tipo de esfuerzo, se habrá adquirido un hábito.

Una vez vistos de manera general los hábitos de estudio, pasamos a centrarnos en las técnicas y comenzamos con una pregunta clave para saber si los alumnos del instituto las usan o no.

¿Estudias la historia directamente de los apuntes/libro de texto? Nos referimos a si leen y estudian la información sin hacer uso de ninguna estrategia para identificar lo principal de lo secundario, recordar lo más importante, etc.

\section{Cuadro 7. Resultados correspondientes a $1^{\circ}$ de ESO. Estudio directo de apuntes}

\begin{tabular}{|l|c|c|}
\hline $1^{\circ}$ ESO & $\begin{array}{c}\text { TOTAL } \\
=135\end{array}$ & $\%$ \\
\hline Nunca & 1 & 0,74 \\
\hline A veces & 2 & 1,48 \\
\hline A menudo & 11 & 8,14 \\
\hline Siempre & 121 & 89,62 \\
\hline
\end{tabular}

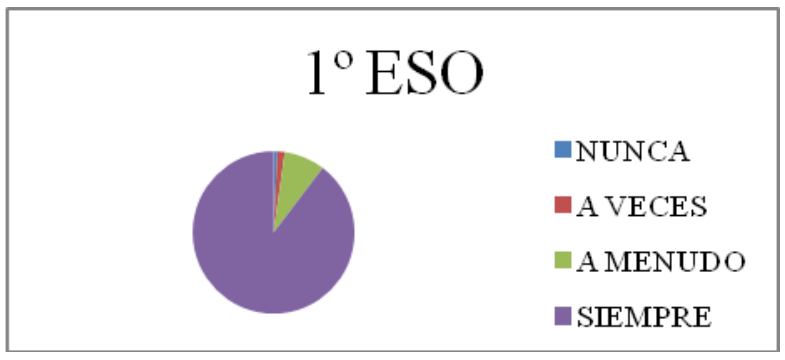

Fuente: Elaboración propia.

Sin lugar a dudas los resultados son escalofriantes. Prácticamente todo el grueso del alumnado del primer curso de secundaria (Véase cuadro 7) no hace uso de ninguna técnica a la hora de estudiar y únicamente leen la información directamente del libro de texto o los apuntes, en su caso. Nos encontramos, por tanto, ante un aprendizaje mecanicista que apuesta por la memorización. Bien es cierto que los profesores de historia, debido a su estática temporalización y a la amplitud de contenidos que han de impartir, no están en condiciones de dedicar el tiempo necesario a trabajar estrategias, pero resulta sorprendente que ni siquiera se haga en las clases de tutoría y se pase por alto, cuando es un grave problema en los primeros cursos de la secundaria, como estamos viendo. 
Cuadro 8. Resultados correspondientes a $4^{\circ}$ de ESO. Estudio directo de apuntes

\begin{tabular}{|l|c|c|}
\hline $4^{\circ}$ ESO & $\begin{array}{c}\text { TOTAL } \\
=50\end{array}$ & $\%$ \\
\hline Nunca & 22 & 44 \\
\hline A veces & 3 & 6 \\
\hline A menudo & 8 & 16 \\
\hline Siempre & 17 & 34 \\
\hline
\end{tabular}

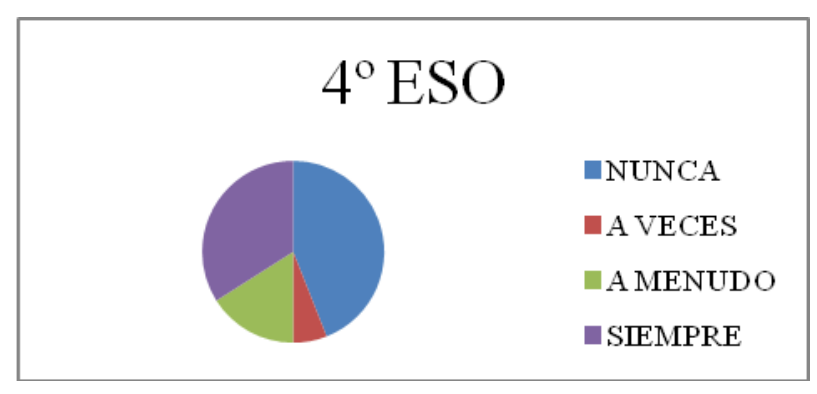

Fuente: Elaboración propia.

En el caso de $4^{\circ}$ de la ESO (Véase cuadro 8) podemos observar la disparidad de modelos de alumnos, es decir, por un lado, casi la mitad de los encuestados no estudia "nunca" directamente del texto, por tanto sí hacen uso de algún método o técnica. Sin embargo, vemos que el $34 \%$ lo hace "siempre", de modo que nos encontramos ante dos tipos de estudiantes muy diferenciados, atreviéndonos a dividirlos en alumnos mecánicos y alumnos significativos.

Cuadro 9. Resultados correspondientes a $2^{\circ}$ de Bachillerato. Estudio directo de apuntes

\begin{tabular}{|l|c|c|}
\hline $2^{\circ}$ BACH & $\begin{array}{c}\text { TOTAL } \\
=96\end{array}$ & $\%$ \\
\hline Nunca & 50 & 52,08 \\
\hline A veces & 30 & 31,25 \\
\hline A menudo & 11 & 11,45 \\
\hline Siempre & 5 & 5,20 \\
\hline
\end{tabular}

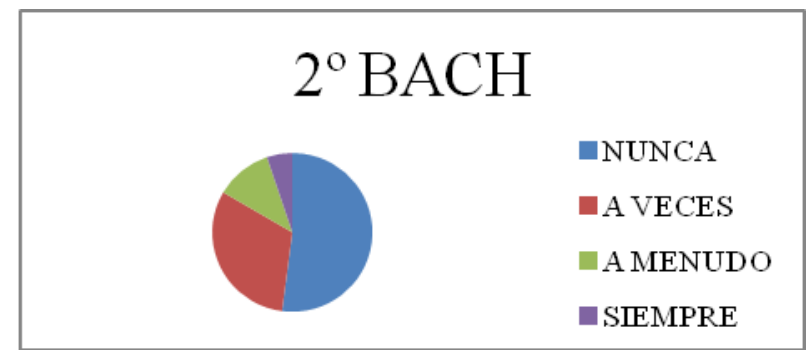

Fuente: Elaboración propia.

Nuevamente observamos que la tendencia es mucho más favorable al aprendizaje en $2^{\circ}$ de bachillerato (Véase cuadro 9) que en los cursos inferiores. Si las pruebas PAU suponen una presión continuada para el alumnado, bien es cierto que despiertan en ellos el interés y la motivación necesaria para intentar asimilar a lo largo del curso el mayor número de contenidos, de ahí que sí hagan uso de recursos efectivos que potencien su adquisición de información histórica.

En relación con la cuestión anterior, hemos querido referirnos a la frecuencia con la que los alumnos hacen uso de esquemas, organigramas o mapas conceptuales para organizar sus conocimientos a cerca de la historia.

¿Realizas esquemas, organigramas o mapas conceptuales para estudiar Historia? 


\section{Cuadro 10. Resultados correspondientes a $1^{\circ}$ de ESO. Organización de la información}

\begin{tabular}{|l|c|c|}
\hline $1^{\circ}$ ESO & $\begin{array}{c}\text { TOTAL } \\
=135\end{array}$ & $\%$ \\
\hline Nunca & 128 & 94,8 \\
\hline A veces & 5 & 3,70 \\
\hline A menudo & 1 & 0,74 \\
\hline Siempre & 0 & 0 \\
\hline
\end{tabular}

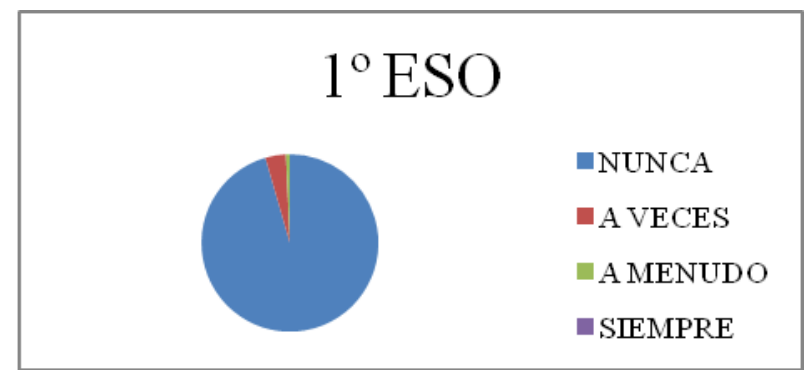

Fuente: Elaboración propia.

Como no es de extrañar una vez analizada la pregunta anterior, la frecuencia con la que se hace uso de las técnicas ya mencionadas es mínima y de un total de 135 alumnos, 128 afirman no haber hecho nunca un esquema, en $1^{\circ}$ de la ESO (Véase cuadro 10) sí es verdad, hablando con ellos, que los usan en ocasiones para estudiar pero que los memorizan directamente del libro del texto e incluso el profesor se los facilita ya elaborados. Claro está que lo más beneficioso de estos recursos es el hecho de que sea el propio alumno quien busque la información, la seleccione y en base a ella realice el esquema o el mapa conceptual, restando eficacia al aprendizaje si les ahorramos todo este trabajo, pues situamos al alumno como elemento pasivo de su aprendizaje.

\section{Cuadro 11. Resultados correspondientes a $4^{\circ}$ de ESO. Organización de la información}

\begin{tabular}{|l|c|c|}
\hline $4^{\circ}$ ESO & $\begin{array}{c}\text { TOTAL } \\
=50\end{array}$ & $\%$ \\
\hline Nunca & 14 & 28 \\
\hline A veces & 2 & 4 \\
\hline A menudo & 11 & 22 \\
\hline Siempre & 23 & 46 \\
\hline
\end{tabular}

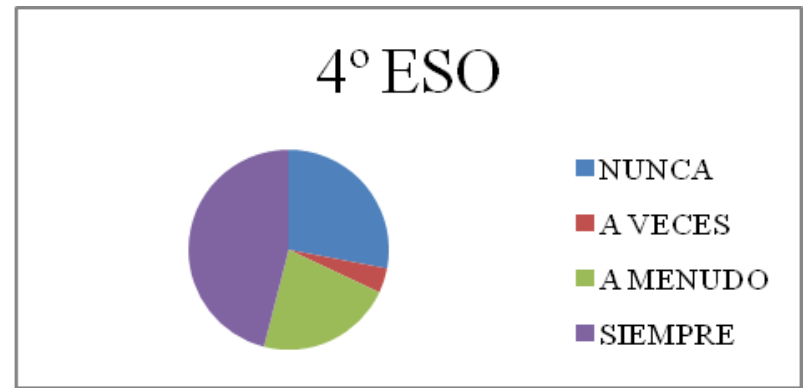

Fuente: Elaboración propia.

Hasta el momento estamos viendo como el grupo de historia de $4^{\circ}$ de la ESO (Véase cuadro 11) supone el punto medio de nuestros cursos de estudio. Parece ser, por tanto, que es el momento en que los alumnos, por cuenta propia, comienzan a reconocer la valía de determinados recursos que incorporan poco a poco a su estudio cotidiano. En la gráfica podemos observar como prácticamente la mitad de alumnos hace uso de alguna de las estrategias de manera asidua, lo cual denota que les son útiles para estudiar, y lo más importante, para aprender. 
Cuadro 12. Resultados correspondientes a $2^{\circ}$ de Bachillerato. Organización de la información

\begin{tabular}{|l|c|c|}
\hline $2^{\circ}$ BACH & $\begin{array}{c}\text { TOTAL } \\
=96\end{array}$ & $\%$ \\
\hline Nunca & 5 & 5,20 \\
\hline A veces & 24 & 2,5 \\
\hline A menudo & 32 & 33,33 \\
\hline Siempre & 35 & 36,45 \\
\hline
\end{tabular}

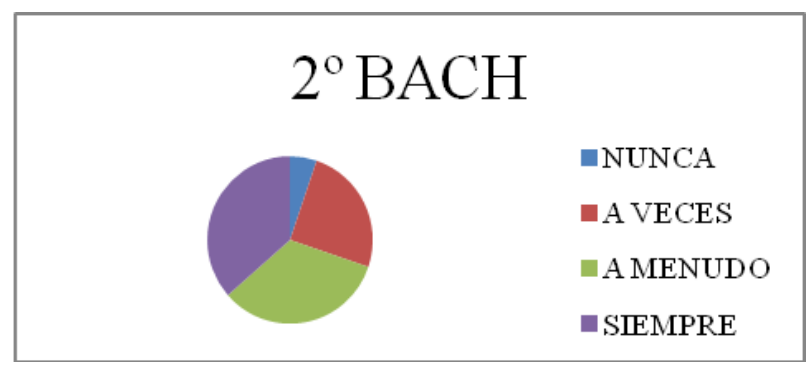

Fuente: Elaboración propia.

En el caso de $2^{\circ}$ de Bachillerato (Véase cuadro 12), solo el $8 \%$ (aproximadamente) de los alumnos no utiliza esquemas, mapas conceptuales u organigramas, con lo cual se trata de un hábito bastante generalizado. Comentando con ellos la cuestión, los alumnos afirman que una vez leída la información histórica objeto de estudio, el hecho de realizar cualquiera de estos recursos les ayuda a retener la información en su cabeza más tiempo. Nos encontramos nuevamente ante técnicas que son usadas con la PAU como precursora, pues los alumnos necesitan estructuras para poder asimilar todo un temario, impartido a lo largo de todo un curso, y que deben tener fresco el día del examen. Recordemos, además, que una de las preguntas de la selectividad actual se centra en un tema trasversal, de modo que si el alumno no tiene una visión de conjunto histórico, difícilmente podrá establecer relaciones con otros temas.

Una vez llegados a este punto, cabe justificar el hecho de que hagamos tanto hincapié en técnicas como el esquema, el mapa conceptual o el organigrama. Pues bien, comenzando por el esquema ${ }^{5}$, no podemos más que referirnos a este como el principal sistema para organizar y resumir la información clave a aprender. Como características indispensables podríamos mencionar que mejora la comprensión, favorece el estudio y simplifica el repaso, siempre y cuando esté elaborado siguiendo las pautas de la claridad y la lógica. Para su confección hemos de tener presente que no debe estar redactado ni ser muy largo, además es preferible que siga los puntos reflejados en el índice.

De igual modo situamos el mapa conceptual como elemento clave en el proceso de E/A de la historia, pues las diferencias con el esquema son mínimas (el esquema es una jerarquía de conceptos y el mapa conceptual una red de conceptos). Se trata de una técnica que, al igual que el esquema tradicional, favorece el "aprender a aprender". Como Novak indica "las técnicas no son una panacea ni un "ábrete sésamo", pero sí pueden ser eficaces". En primer lugar, un mapa de conceptos sobre un tema histórico concreto permite captar de un solo golpe de vista la estructura de toda la información que posteriormente se habrá de aprender, por tanto se genera una previa familiarización con la temática de estudio. Cuando los conceptos están organizados, poseen una estructura lógica y están relacionados entre sí, el mapa conceptual está bien elaborado y por tanto está disponible a ser anexionado a la estructura cognitiva del estudiante, que recordará durante más tiempo todo lo que en este se refleja (memoria visual). Otros beneficios a tener en cuenta son aquellos que permiten al alumno mejorar su capacidad

\footnotetext{
${ }^{5}$ MARTÍNEZ, E. y MAQUEDA, C. La Historia y las Ciencias Humanas. Didáctica y Técnicas de Estudio.
} 
de análisis y síntesis, pues recordemos que la elaboración de todos estos recursos que venimos tratando requiere un previo ejercicio de lectura, comprensión, selección y síntesis de la información.

Analizando ahora las características del organigrama aplicado a la Historia, debemos comenzar por definirlo, para diferenciarlo de los recursos anteriores. El organigrama ${ }^{6}$ es un sistema más estático que el esquema o el mapa conceptual, más fijo en su composición y más conciso en su contenido. Más que sintetizar contenidos, se centra en esclarecer los significados de los mismos y en relacionar unos conceptos con otros, creando una secuencia que de sentido al proceso histórico a estudiar. Su mayor complejidad respecto al esquema o el mapa hace que sea uno de los recursos más desconocidos e inusuales entre los alumnos de instituto.

Aprovechando que nos encontramos tratando el tema de los conceptos, cabe mencionar brevemente otro problema de gran frecuencia e importancia; la falta de consolidación en el alumnado de los conceptos estructurantes de la historia ${ }^{7}$. Nos referimos con ello a los términos que rigen los periodos históricos, independientemente de cuáles sean y cabe hacer mención especial a la "cronología", "cambio", "continuidad", "tiempo", "secuencia", "causa", "efecto". Si todos estos términos 8 no están claros, difícilmente vamos a obtener un aprendizaje significativo, por muchos recursos, técnicas o métodos que utilicemos. Por ejemplo, comprender el significado de "secuencia" o "cronología" permite establecer en nuestros esquemas un orden lógico de los hechos sin el cual no podríamos comprender los procesos históricos.

En lo que respecta a las técnicas que consideramos más extendidas están entre los alumnos de Secundaria y Bachiller no podemos más que destacar el uso del subrayado, otra de las variables de análisis del presente trabajo. Su importancia radica en la necesidad de tener identificada la información principal para luego traspasarla al esquema o resumen que el estudiante vaya a usar en su aprendizaje.

Así, ante la pregunta ¿subrayas la información? éstas son las respuestas obtenidas.

Cuadro 13. Resultados correspondientes a $1^{\circ}$ de ESO. Subrayado de información

\begin{tabular}{|l|c|c|}
\hline $1^{\circ}$ ESO & $\begin{array}{c}\text { TOTAL } \\
=135\end{array}$ & $\%$ \\
\hline Nunca & 1 & 0,74 \\
\hline A veces & 4 & 2,96 \\
\hline A menudo & 23 & 17,03 \\
\hline Siempre & 107 & 79,25 \\
\hline
\end{tabular}

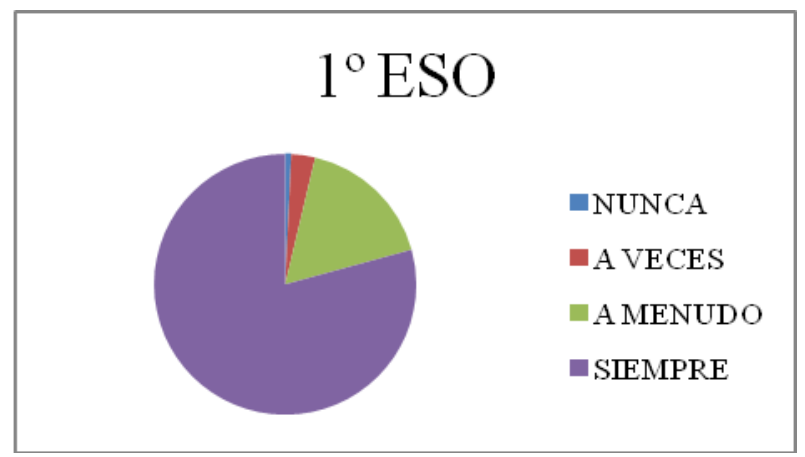

Fuente: Elaboración propia.

Apreciamos de manera visual en la gráfica (Véase el cuadro 13) y sin necesidad de retenernos mucho en ella que más de las tres partes del alumnado de primero de

\footnotetext{
${ }^{6}$ MARTÍNEZ, E. y MAQUEDA, C. La Historia y las Ciencias Humanas. Didáctica y técnicas de Estudio.

${ }^{7}$ SEBASTIÁ, R. Innovación e investigación en Didáctica de las Ciencias Sociales: Historia.

${ }^{8}$ PLUCKROSE, H. Enseñanza y aprendizaje de la historia.
} 
Educación Secundaria "siempre" subraya el libro de texto. En estos cursos de menor nivel, es muy frecuente encontrar el subrayado dentro de la metodología habitual del profesor, quien en muchos casos, y probablemente así sea en este concreto, debido al alto porcentaje de su uso, dictan a los alumnos aquello que han de subrayar en el texto. Probablemente este método se deba a la premura con que tienen que impartirse los temas a fin de acabar el temario, pues diciendo al alumnado que es lo que tiene que subrayar se ahorra más tiempo que si le explicamos cómo seleccionar la información principal. Sin embargo, es imprescindible para el desarrollo del conocimiento de los alumnos que sepan identificar las ideas importantes de las que no lo son, si lo es en todas las materias, en la de historia su relevancia se multiplica.

\section{Cuadro 14. Resultados correspondientes a $4^{\circ}$ de ESO. Subrayado de información}

\begin{tabular}{|l|c|c|}
\hline $4^{\circ}$ ESO & $\begin{array}{c}\text { TOTAL } \\
=50\end{array}$ & $\%$ \\
\hline Nunca & 1 & 2 \\
\hline A veces & 1 & 2 \\
\hline A menudo & 5 & 10 \\
\hline Siempre & 43 & 86 \\
\hline
\end{tabular}

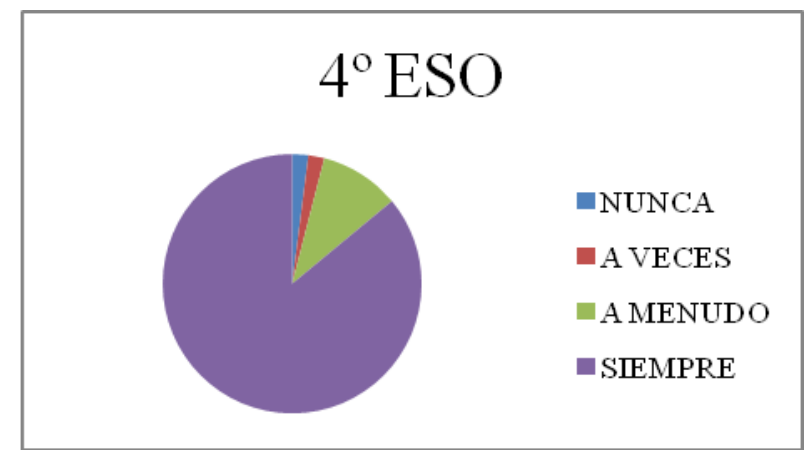

Fuente: Elaboración propia.

Intuimos que los alumnos de $4^{\circ}$ de ESO comienzan a ser más autónomos en su proceso de aprendizaje, de ahí que la utilización de diversas estrategias vaya tomando una forma más adecuada (Véase el cuadro 14) Sucede lo mismo con el uso de subrayado, pues como vemos prácticamente la totalidad de alumnos usa "siempre" o "a menudo" la técnica que venimos tratando. Confiamos que esta actividad se realice previamente a la elaboración de esquemas propios que favorezcan el aprendizaje "procedimental", es decir, el que se adquiere "haciendo".

\section{Cuadro 15. Resultados correspondientes a $2^{\circ}$ de Bachillerato. Subrayado de la} información

\begin{tabular}{|l|l|l|}
\hline $2^{\circ}$ BACH & $\begin{array}{l}\text { TOTAL } \\
=96\end{array}$ & $\%$ \\
\hline Nunca & 3 & 3,12 \\
\hline A veces & 2 & 2,08 \\
\hline A menudo & 53 & 55,20 \\
\hline Siempre & 38 & 39,58 \\
\hline
\end{tabular}

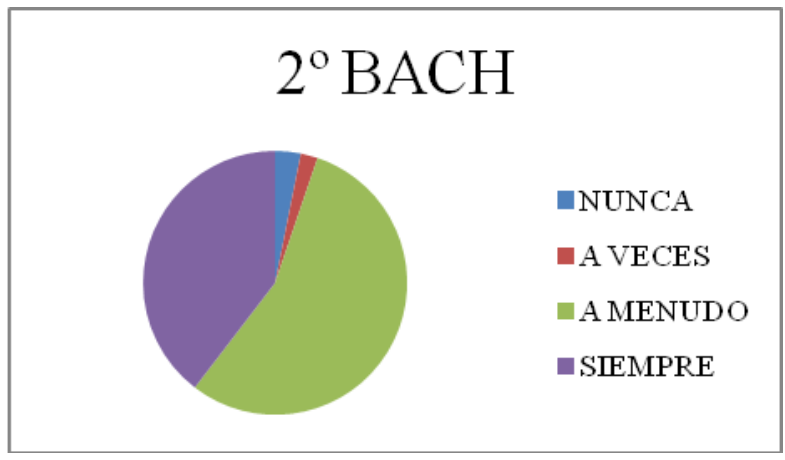

Fuente: Elaboración propia. 
Más o menos atisbamos los mismos resultados en lo que respecta a $2^{\circ}$ de bachiller (Véase cuadro 15), pues si bien es menor el número de alumnos que subraya "siempre", aumenta el que lo hace frecuentemente o "a menudo". Nuevamente hemos de hacer referencia en este caso a la necesidad de seleccionar contenidos que sean primordiales para entender el tema en general, pues para cualquier persona es imposible aprender toda la información al detalle sin destacar lo más importante, a partir de lo cual se puede ir asimilando el resto.

El subrayado, como ya planteábamos antes de realizar el cuestionario y como hemos corroborado una vez analizados los datos, es una estrategia muy recurrente y usada por casi todos los alumnos de manera usual. Este sistema, ya tradicional, hace que la atención del estudiante quede centrada en aquellas palabras o frases claves que permitirán la comprensión total de los contenidos. En lo que se refiere a la técnica, cada alumno ha de escoger la que más se adecue a sus preferencias, aunque la más recomendada es sin duda el uso de diferentes colores que marquen la jerarquía o importancia de las ideas que se seleccionan. La principal ventaja la encontramos a la hora de efectuar el repaso, pues únicamente leyendo las líneas subrayadas recordaremos toda la información que nos interesa.

Continuando con el cuestionario del que partimos, pasamos a analizar la ejecución o no de resúmenes para estudiar los temas históricos vistos en clase. Justificamos esta pregunta teniendo en cuenta que, a simple vista, el resumen parece ser un recurso bastante generalizado y consideramos que es uno de los más trabajados en el aula, a través de actividades. Además, ya en la primaria se introduce esta técnica con el fin de enseñar al niño a sintetizar la información. De este modo pretendemos comprobar si es cierta la idea previa que considera a esta técnica como la más extendida dentro del aprendizaje propio del estudiante.

A la hora de estudiar historia, ¿haces resúmenes?

\section{Cuadro 16. Resultados correspondientes $1^{\circ}$ de ESO. Elaboración de resúmenes}

\begin{tabular}{|l|c|c|}
\hline $1^{\circ}$ ESO & $\begin{array}{c}\text { TOTAL } \\
=135\end{array}$ & $\%$ \\
\hline Nunca & 87 & 64,44 \\
\hline A veces & 11 & 8,14 \\
\hline A menudo & 23 & 17,03 \\
\hline Siempre & 14 & 10,37 \\
\hline
\end{tabular}

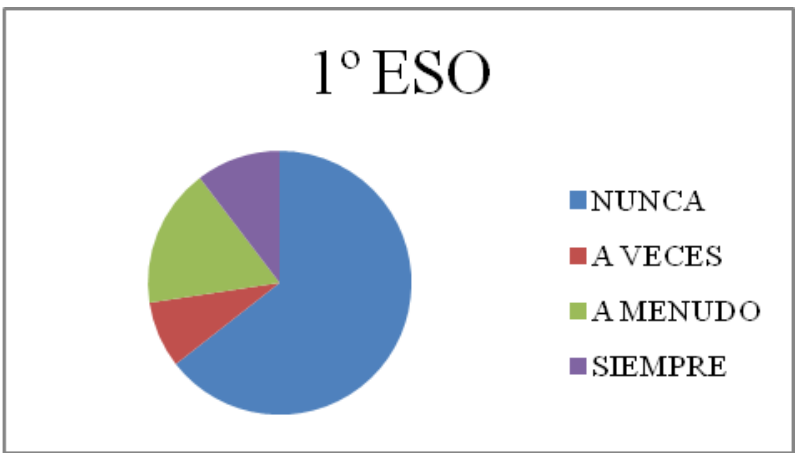

Fuente: Elaboración propia.

Como vemos en el cuadro 16, aunque ya en el colegio se comience a trabajar el resumen, nos encontramos en un $1^{\circ}$ de ESO donde más del $60 \%$ de los alumnos no lo utiliza de forma asidua para el estudio de la historia y únicamente el $10 \%$ lo hace siempre para asimilar mejor cada uno de los temas. De este modo, aunque aparece en una posición ligeramente más favorable respecto a los recursos anteriormente vistos, el 
resumen todavía no adquiere un uso eficaz y constante en el aprendizaje de alumnos de los cursos más tempranos de la Secundaria.

Cuadro 17. Resultados correspondientes a $4^{\circ}$ de ESO. Elaboración de resúmenes

\begin{tabular}{|l|c|c|}
\hline $4^{\circ}$ ESO & $\begin{array}{c}\text { TOTAL } \\
=50\end{array}$ & $\%$ \\
\hline Nunca & 3 & 6 \\
\hline A veces & 9 & 18 \\
\hline A menudo & 17 & 34 \\
\hline Siempre & 21 & 42 \\
\hline
\end{tabular}

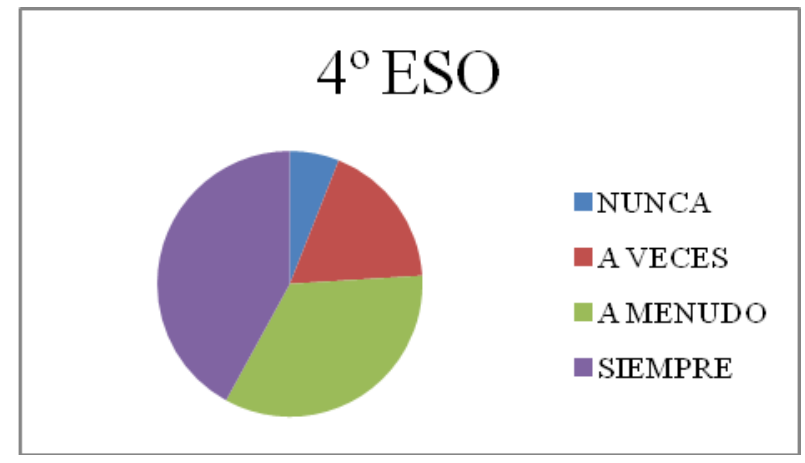

Fuente: Elaboración propia.

Observando este nuevo gráfico (Véase cuadro 17) observamos una diferencia abismal respecto al anterior, pues en $4^{\circ}$ de la ESO solamente una cuarta parte de los alumnos no utiliza el resumen como instrumento para su estudio.

\section{Cuadro 18. Resultados correspondientes a $2^{\circ}$ de Bachillerato. Elaboración de resúmenes}

\begin{tabular}{|l|c|c|}
\hline $2^{\circ}$ BACH & $\begin{array}{c}\text { TOTAL } \\
=96\end{array}$ & $\%$ \\
\hline Nunca & 2 & 2,08 \\
\hline A veces & 7 & 7,29 \\
\hline A menudo & 26 & 27.08 \\
\hline Siempre & 61 & 63,59 \\
\hline
\end{tabular}

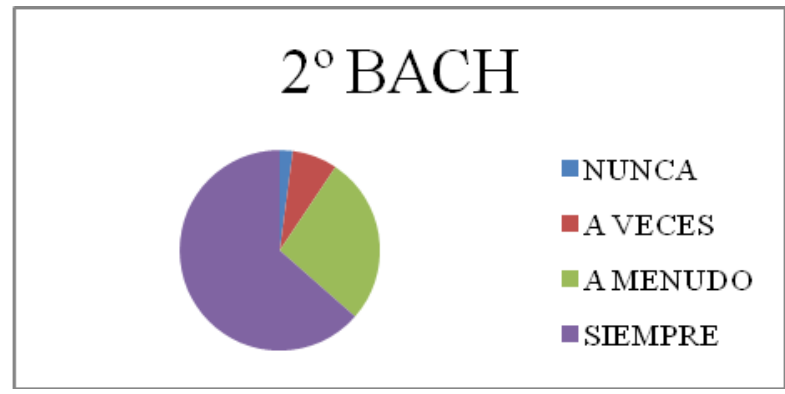

Fuente: Elaboración propia.

La situación evoluciona favorablemente, al igual que el uso de los demás métodos, una vez llegados al bachillerato, como nos indica el cuadro 18, pues parece que prácticamente la totalidad del alumnado tiene adherido el resumen a su propia metodología de aprendizaje.

Parece ser que, como afirmábamos al principio, el resumen es una de las estrategias más usadas en el aula y su conocimiento por parte del alumno hace que inconscientemente se mentalice de su valía y lo incorpore a sus hábitos de trabajo. El hecho de que el resumen sea un método más generalizado que los esquemas o mapas conceptuales no se encuentra tanto en que sea más o menos eficaz que estos, sino en que el alumnado, al contar en sus resúmenes con la información simplificada pero redactada, adquiere una 
mayor seguridad respecto a la expresión de ideas, pues la expresión escrita es otro de los grandes problemas de la educación de nuestros jóvenes. Esto es, mientras en el esquema únicamente apuntamos las ideas, sin redacción alguna, en el resumen sí aplicamos el desarrollo, por tanto el memorizar la frase en sí permite al alumno reflejarla tal cual en el examen, sin necesidad de pensar en cómo explicar aquello que en el esquema aparecía representado con dos palabras.

Por tanto, consideramos como resumen ${ }^{9}$ la simplificación de la información de estudio, mostrando por escrito las ideas principales y sus interrelaciones, sin superar el $25 \%$ del total de la información. Este trabajo requiere, además, la condensación selectiva de la información, así como el mantenimiento de la estructura lógica del material original. De este modo, se sigue el orden en el que aparecen las ideas del material de referencia y se recogen solo aquellas necesarias para entender las claves de la información. El objetivo principal del resumen no es otro que la comprensión global por parte del alumno del contenido histórico a estudiar.

Cambiando de tercio, uno de los elementos que se consideran más útiles para adquirir un aprendizaje eficaz es el "descubrimiento", que en el caso del estudio de la historia lo entendemos como la búsqueda de nueva información ${ }^{10}$. No cabe duda que el hecho de buscar nuevas fuentes sobre un tema y contrastar las ideas que podemos encontrar es imprescindible para el desarrollo de la crítica. Además, la consulta de bibliografía más allá de los contenidos curriculares que el profesor expone en clase, permite al alumno generar una visión propia de la problemática planteada, favoreciendo la comprensión y la retención de la información.

Pero, ¿usan los alumnos de Secundaria y Bachiller otras fuentes? ¿Buscan información? Veamos.

Cuadro 19. Resultados $1^{\circ}$ de ESO. Búsqueda de información

\begin{tabular}{|l|c|c|}
\hline $1^{\circ}$ ESO & $\begin{array}{c}\text { TOTAL } \\
=135\end{array}$ & $\%$ \\
\hline Nunca & 131 & 97,03 \\
\hline A veces & 3 & 2,22 \\
\hline A menudo & 1 & 0,74 \\
\hline Siempre & 0 & 0 \\
\hline
\end{tabular}

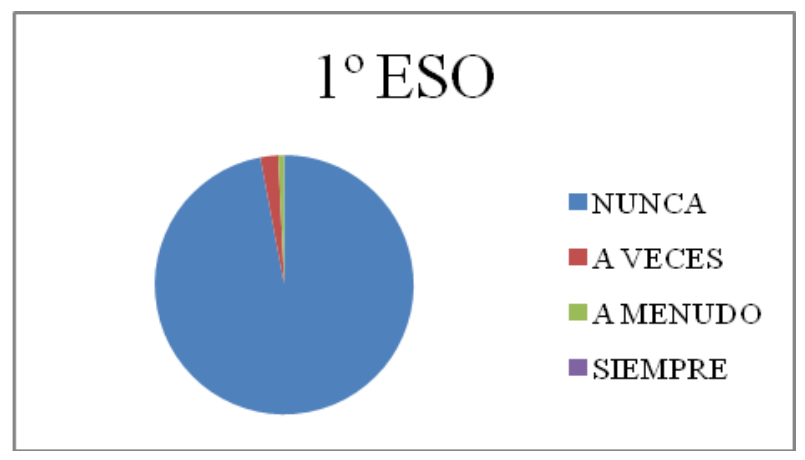

Fuente: Elaboración propia.

Como no es de extrañar, teniendo en cuenta que son alumnos todavía muy pequeños, la búsqueda de información es para el Primer Curso de Secundaria algo que se sale de lo habitual (Véase el cuadro 19) Es en estos momentos cuando el docente debe iniciar al niño de 12 años en la búsqueda de nuevos materiales, ya sean libros o páginas de

\footnotetext{
${ }^{9}$ GONZÁLEZ, R., GONZÁLEZ-PIENDA J. A. y otros. Estrategias y Técnicas de Estudio.

${ }^{10}$ SALAS, M. Técnicas de Estudio para Secundaria y Universidad.
} 
internet, películas o demás recursos que pensamos les pueden resultar motivadores. Introduciendo tareas de indagación, el alumno puede sentirse atraído por la materia, adquiriendo un rol de investigador que suele resultar fascinante.

Cuadro 20. Resultados correspondientes a $4^{\circ}$ de ESO. Búsqueda de información

\begin{tabular}{|l|c|c|}
\hline $4^{\circ}$ ESO & $\begin{array}{c}\text { TOTAL } \\
=50\end{array}$ & $\%$ \\
\hline Nunca & 42 & 84 \\
\hline A veces & 7 & 14 \\
\hline A menudo & 1 & 2 \\
\hline Siempre & 0 & 0 \\
\hline
\end{tabular}

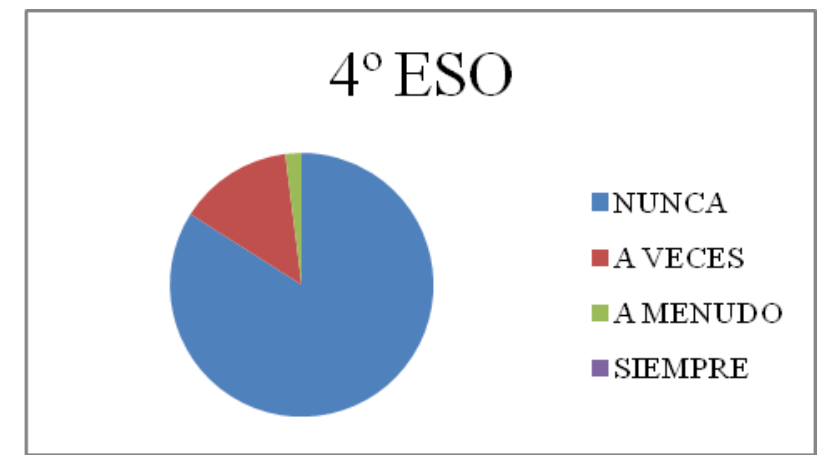

Fuente: Elaboración propia.

Analizando la gráfica correspondiente al cuadro 20, sobre el uso de bibliografía extra en alumnos de $4^{\circ}$ de la ESO, podemos contemplar que sigue sin ser usual, pues el $90 \%$ de los alumnos no lo hace. Observamos pues que se trata de un hábito que los estudiantes no consideran necesario, limitándose a estudiar aquello que los profesores plantean.

Cuadro 21. Resultados $2^{\circ}$ de Bachillerato. Búsqueda de información

\begin{tabular}{|l|c|c|}
\hline $2^{\circ} \mathrm{BACH}$ & $\begin{array}{c}\text { TOTAL } \\
=96\end{array}$ & $\%$ \\
\hline Nunca & 72 & 75 \\
\hline A veces & 13 & 13,54 \\
\hline A menudo & 9 & 9,37 \\
\hline Siempre & 2 & 2,08 \\
\hline
\end{tabular}

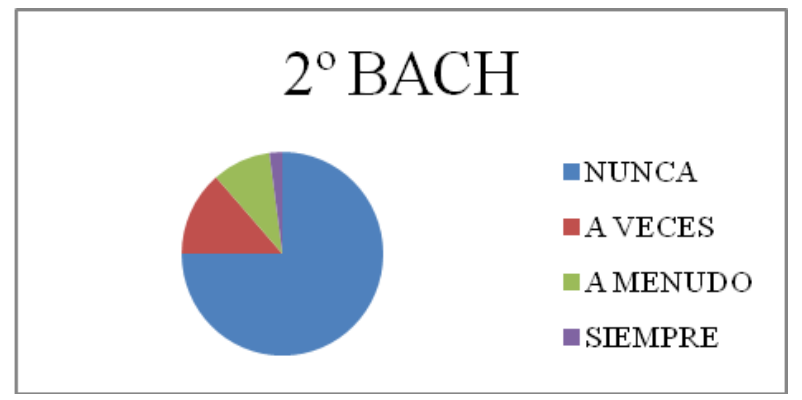

Fuente: Elaboración propia.

Aunque los resultados son levemente superiores en bachillerato, en cuanto a la búsqueda de información, todavía no es una cuestión asimilada completamente (Véase cuadro 21) En este caso entendemos que los pocos alumnos que lo hacen se sienten especialmente motivados e interesados por alguno de los temas y de ahí procede que se practique este ejercicio.

En conclusión, vemos que los alumnos de instituto se limitan a estudiar aquello que se les ofrece en clase. Cuestionamos, así, la existencia de un espíritu crítico, ya que se "creen" todo lo que el profesor les dice, adquiriendo de este modo una actitud muy pasiva, que no beneficia en absoluto al proceso de E/A. 
Por último, pretendemos obtener la información relativa al proceso de asimilación de conocimientos, esto es, saber si los alumnos únicamente memorizan o si por el contrario entienden lo que estudian. En todo momento hemos de tener presente que el aprendizaje de la historia requiere de la memoria, eso es cierto, no obstante, lo que pretendemos combatir es la memorización sin comprensión.

Ante la pregunta ¿memorizas toda la información?, recopilamos los siguientes datos:

\section{Cuadro 22. Resultados $1^{\circ}$ ESO. Memorización de la información}

\begin{tabular}{|l|c|c|}
\hline $1^{\circ} \mathrm{ESO}$ & $\begin{array}{c}\text { TOTAL } \\
=135\end{array}$ & $\%$ \\
\hline Nunca & 2 & 1,48 \\
\hline A veces & 0 & 0 \\
\hline A menudo & 5 & 3,70 \\
\hline Siempre & 128 & 94,81 \\
\hline
\end{tabular}

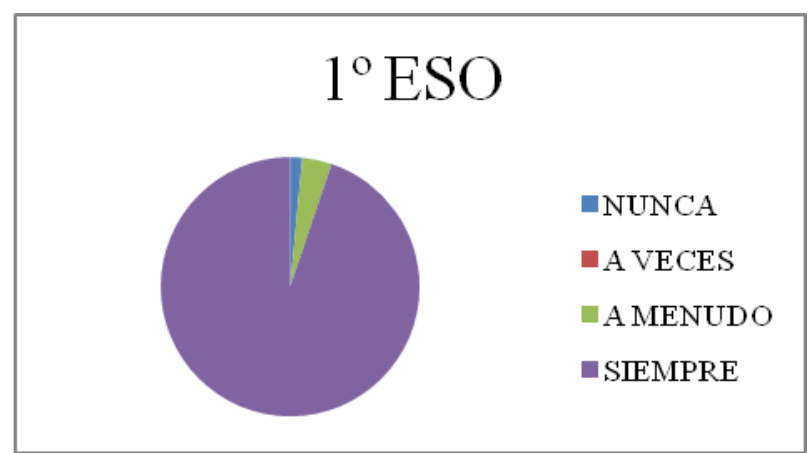

Fuente: Elaboración propia.

El grueso del alumnado de este curso (95\%) (Véase cuadro 22) "siempre" memoriza la información de los libros de texto y, teniendo en cuenta, como ya hemos podido observar, que no recurren a estrategias de estudio, deducimos que lo memorizan mecánicamente, frase a frase y de manera automática.

\section{Cuadro 23. Resultados $4^{\circ}$ ESO. Memorización de la información}

\begin{tabular}{|l|c|c|}
\hline $4^{\circ}$ ESO & $\begin{array}{c}\text { TOTAL } \\
=50\end{array}$ & $\%$ \\
\hline Nunca & 1 & 2 \\
\hline A veces & 2 & 4 \\
\hline A menudo & 8 & 16 \\
\hline Siempre & 39 & 78 \\
\hline
\end{tabular}

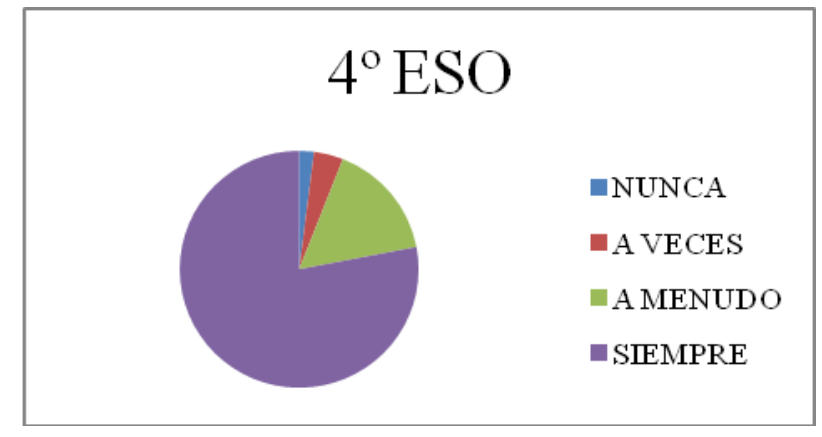

Fuente: Elaboración propia.

La tendencia se mantiene, aunque con un porcentaje algo menor, entre los alumnos de $4^{\text {o }}$ de la ESO (Véase cuadro 23) Observamos que tres cuartos del total memoriza toda la información "siempre" y prácticamente el resto lo hace "a menudo". 
Cuadro 24. Resultados $2^{\circ}$ de Bachillerato. Memorización de la información

\begin{tabular}{|l|c|c|}
\hline $2^{\circ}$ BACH & $\begin{array}{c}\text { TOTAL } \\
=96\end{array}$ & $\%$ \\
\hline Nunca & 2 & 2,08 \\
\hline A veces & 5 & 5,20 \\
\hline A menudo & 21 & 21,87 \\
\hline Siempre & 68 & 70,83 \\
\hline
\end{tabular}

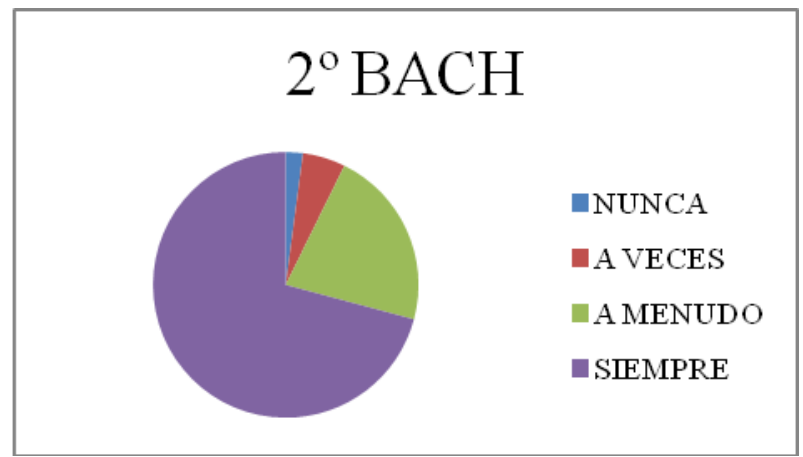

Fuente: Elaboración propia.

Llegamos a bachillerato (Véase el cuadro 24) sin que se haya reducido el estudio mecanicista, pues vemos que la parte violeta sigue siendo predominante en nuestra gráfica circular, y esto a pesar de usar cotidianamente recursos de estudio que consideramos efectivos.

Contra nuestros deseos, podemos concluir con la indiscutible preeminencia del aprendizaje mecanicista que tanto venimos rechazando en estas líneas. Este tipo de estudio "conductista" no hace más que retener la información en la memoria a corto plazo en el alumno, que además, seguramente memorice conceptos que ni siquiera comprende.

En relación con este último aspecto, concluimos nuestra encuesta intentando comprobar si, al menos y a pesar del predominio absoluto de la memorización, los alumnos comprenden aquello que estudian. Los resultados son los siguientes:

Cuadro 25. Resultados $1^{\circ}$ ESO. Comprensión de la información

\begin{tabular}{|l|c|c|}
\hline $1^{\circ} \mathrm{ESO}$ & $\begin{array}{c}\text { TOTAL } \\
=135\end{array}$ & $\%$ \\
\hline Nunca & 6 & 4,44 \\
\hline A veces & 19 & 14,07 \\
\hline A menudo & 23 & 17,03 \\
\hline Siempre & 87 & 64,44 \\
\hline
\end{tabular}

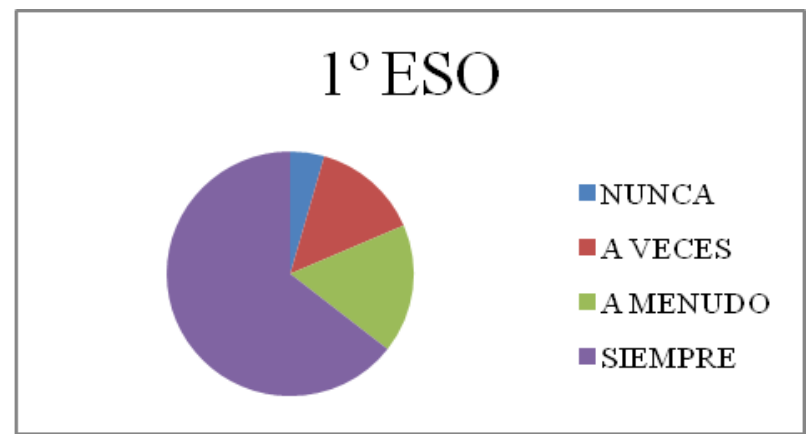

Fuente: Elaboración propia.

Viendo los datos de la presente gráfica (Véase cuadro 25), nos reconforta descubrir que, aunque se recurra a la memorización, los alumnos de $1^{\circ}$ de ESO sí comprenden lo que estudian, en su mayoría. Este hecho es un logro, pues a pesar de la escasa dificultad que pueda presentar en estos cursos el aprendizaje de la historia, bien es cierto que los 
alumnos se encuentran en una edad en que la motivación y el interés por la asignatura no son precisamente constantes.

Cuadro 26. Resultados $4^{\circ}$ ESO. Comprensión de la información

\begin{tabular}{|l|c|c|}
\hline $4^{\circ}$ ESO & $\begin{array}{c}\text { TOTAL } \\
=50\end{array}$ & $\%$ \\
\hline Nunca & 0 & 0 \\
\hline A veces & 5 & 10 \\
\hline A menudo & 42 & 84 \\
\hline Siempre & 3 & 6 \\
\hline
\end{tabular}

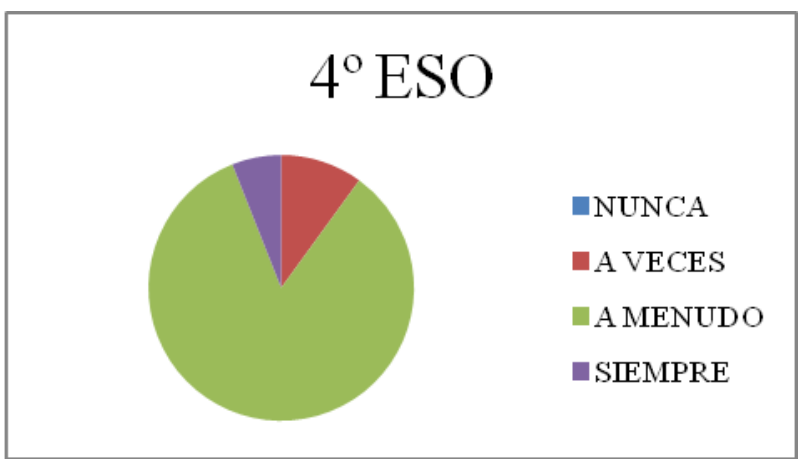

Fuente: Elaboración propia.

Nos sorprende, por otro lado, que en la comprensión de contenidos del alumnado de $4^{\circ}$ de ESO sea cuantiosamente mayor el número de personas que suelen comprender lo que estudian que quienes lo hacen "siempre" (véase cuadro 26) Esto nos da a conocer que a la hora de estudiar, los alumnos no intentan resolver aquellas dudas que se les presenta, memorizando sin más y sin dar la importancia suficiente a la presencia de lagunas, que quizá, en algunos casos lleguen a ser insalvables, pero que pasan desapercibidas al responder la memoria por ellas.

Cuadro 27. Resultados $2^{\circ}$ de Bachillerato. Comprensión de la información

\begin{tabular}{|l|c|c|}
\hline $2^{\circ}$ BACH & $\begin{array}{c}\text { TOTAL } \\
=96\end{array}$ & $\%$ \\
\hline Nunca & 0 & 0 \\
\hline A veces & 3 & 3,12 \\
\hline A menudo & 19 & 19,79 \\
\hline Siempre & 74 & 77,08 \\
\hline
\end{tabular}

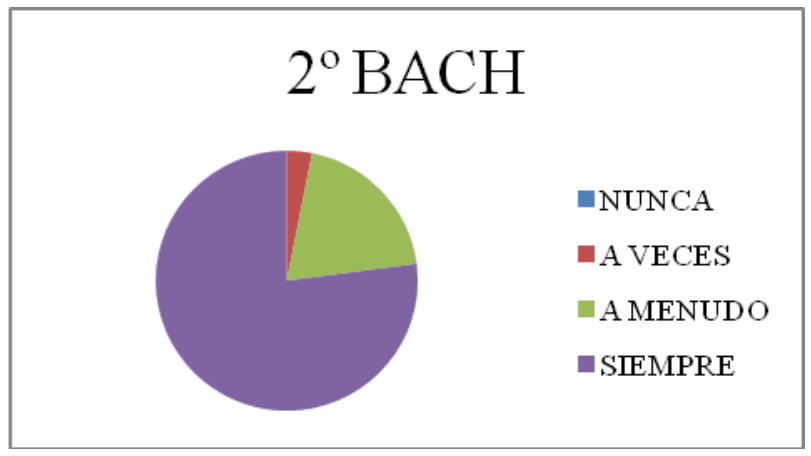

Fuente: Elaboración propia.

Analizando, por último, los resultados obtenidos en bachillerato (Véase cuadro 27), podemos ver que prácticamente todos los alumnos entienden aquello que estudian. Hemos de tener en cuenta que nos encontramos ante un alumnado que ya no pertenece a la Enseñanza Obligatoria, es decir, que continúa sus estudios por voluntad propia, para conseguir sus propias metas. No es de extrañar así que, en el caso de que algo no comprenda, se busquen los medios necesarios para despejar sus dudas, y todavía más si 
tenemos en cuenta la selectividad, una prueba que marca sustanciosamente la progresión de los alumnos de este curso.

\section{CONCLUSIONES}

A modo de recopilación informativa a cerca de todas las variables que hemos ido analizando en el apartado anterior, podemos afirmar de manera concisa que el aprendizaje de la historia en los alumnos del instituto se hace progresivamente más significativo a medida que se va avanzando de curso. Del mismo modo hemos de mencionar la edad como factor clave en la madurez intelectual del estudiante y por consiguiente en la búsqueda de recursos y estrategias que le permita adquirir los conocimientos planteados en el currículo de una forma eficaz que haga que dichos contenidos perduren en la memoria, a ser posible, para siempre.

Hemos podido observar, mediante cuestiones concretas, que los alumnos de $1^{\circ}$ de ESO todavía mantienen una metodología propia de la primaria, donde el aprendizaje depende exclusivamente de la gestión del docente. A medida que los alumnos pasan de nivel, van convirtiéndose de manera progresiva en los protagonistas de su proceso de E/A y el profesor actúa como guía, pero no es la figura fundamental.

Por otro lado, vemos que esta madurez se materializa en la utilización de adecuados métodos de estudio entre los cuales destacamos, por su utilidad y fácil aplicación, el subrayado, el resumen y el esquema o mapa conceptual. Como venimos afirmando durante todo el escrito, la importancia de clarificar ideas e identificarlas dentro de un contexto concreto es el primer paso para la comprensión histórica, de ahí que reivindiquemos firmemente la instrucción de los alumnos en estas técnicas metodológicas activas. Además, la iniciación estudiantil en la búsqueda de material histórico sigue siendo escasa, por no decir nula, pues independientemente del curso o la edad, los alumnos no están familiarizados en absoluto con la indagación ${ }^{11}$, a pesar de suponer un paso fundamental para alcanzar una consolidada asimilación cognitiva.

La memorización, por su parte, sigue siendo la protagonista del aprendizaje y, como ya dijimos anteriormente, es necesaria, pero siempre y cuando aparezca respaldada por la comprensión histórica. Más que la acumulación de datos y fechas, la historia consta de los procesos en que estos hechos se encuentran inmersos, las causas y las consecuencias. Para comprender los procesos no es necesario que sepamos exactamente el año y el mes de tal acontecimiento, basta con entender lo que ese acontecimiento significó dentro de su marco histórico. Por ello, aunque hemos llegado a la conclusión de que los estudiantes encuestados mayoritariamente sí comprenden aquello que estudian, el hecho de que lo asimilen memorísticamente sin hacer uso de los procedimientos que aquí defendemos resta valía y rigurosidad a su aprendizaje de la historia, que además, ha de estar perfectamente planificado y organizado, siendo este un hábito no demasiado extendido.

Por último, hemos de destacar la práctica unanimidad entre los autores sobre la eficacia de las técnicas y métodos a la hora de afrontar el aprendizaje de la historia. Cierto es que cada cual considera más útil uno u otro, dependiendo claro está de su propia experiencia personal, pero no existe discusión en cuanto a su vigor. Es, por tanto, un

\footnotetext{
${ }^{11}$ SEBASTIÁ, R. Innovación e Investigación en Didáctica de las Ciencias Sociales: Historia.
} 
pensamiento generalizado que la aplicación práctica de estrategias de estudio es imprescindible para alcanzar el éxito académico.

Concluimos el presente trabajo mostrando una propuesta metodológica de estudio, es decir, identificando los pasos que consideramos indispensables para el correcto aprendizaje de la historia, aplicable a cualquier alumno, sea cual sea su edad o curso académico. Pasamos a enumerar los pasos:

1) Exploración. El primer paso a la hora de iniciar el estudio de la historia es explorar el material a estudiar en su totalidad, pues así el alumno adquirirá una visión de conjunto, se familiarizará con el tema en cuestión y observará la importancia de los diferentes apartados en relación con la idea principal.

2) Pre-lectura. Nos referimos con ello a una primera lectura rápida de toda la información, sin pararse a realizar anotaciones o a subrayar. Así, el alumno captará las ideas principales y su relación jerárquica.

3) Lectura comprensiva. Pasamos a la lectura activa, razonada y comprensiva del texto. Esta se hace subrayando la información primordial y buscando en el diccionario aquellas palabras que le resultan desconocidas al estudiante. El razonamiento y la comprensión en este sentido son imprescindibles para poder desdeñar el significado de cada frase dentro del contexto o marco histórico en que se encuentra.

4) Subrayado. Como ya hemos visto, el subrayado sería una actividad simultánea a la lectura comprensiva y se recomienda el uso de colores para organizar la jerarquía de ideas. Este recursos es útil sobre todo a la hora de efectuar el repaso, pues la vista únicamente se centra en la información marcada, ahorrando tiempo y esfuerzo.

5) Organización de la información. A menudo, la información aparece lógicamente ordenada en el material original, pero otras veces el alumno prefiere reestructurarla para entenderla mejor, "personalizarla". La estructura en la que se configura la información es clave para la comprensión de la misma, por ello el alumno debe adecuar los contenidos según sus propios criterios.

6) Esquematización. Una vez subrayada la información, es conveniente que el alumno la transforme en una representación gráfica que favorezca la memoria visual y donde existan lazos de dependencia entre las ideas principales, las secundarias e incluso los detalles y anécdotas. Mientras se está realizando el esquema o mapa conceptual, la concentración del estudiante es máxima, al encontrarse ocupado. Entre sus principales ventajas destaca la visión de conjunto que se adquiere con un único golpe de vista.

7) Síntesis. Dentro del proceso de E/A, este apartado, aunque recomendable, no es imprescindible. A través de la síntesis pretendemos que el alumno, una vez leída la información, subrayada y esquematizada, sea capaz de explicar con sus palabras el tema de estudio, sin recurrir a los materiales. Como decimos es útil, pues sirve como afianzamiento de los conocimientos, pero si la premura de tiempo requiere prescindir de un paso ha de ser este.

8) Repaso. El último paso y uno de los más importantes es el repaso. Con su aplicación, el alumno comprobará si recuerda lo estudiado y cuanto más veces se realice más grabado quedará lo estudiado en la memoria. 
Si el alumno realiza estos ocho pasos en el estudio de la historia, difícilmente no obtendrá el éxito. A estas pautas hemos de sumar otros factores que, del mismo modo intervienen directamente en el aprendizaje. Estos son, por un lado los factores ambientales que ya comentábamos; lugar de estudio, temperatura, postura, luz... y sobre todo los factores internos, materializados en la relajación, la concentración y por supuesto, la motivación.

Es imprescindible continuar trabajando y reivindicando la instrucción de estrategias que faciliten al alumnado el aprendizaje de la historia, pues resulta necesario combatir el fracaso escolar y la aptitud de los alumnos hacia la asignatura, una asignatura que, además de su interés conceptual, cobra mucha importancia en cuanto a su implicación en la educación en valores, desarrollando, por tanto, de forma indirecta, la propia personalidad de nuestros alumnos.

\section{BIBLIOGRAFÍA}

CARRETERO, M. y LIMÓN, M. Aportaciones de la psicología cognitiva y de la instrucción a la enseñanza de la historia y las Ciencias Sociales. Infancia y Aprendizaje. Journal for the Study of Education and Development, 1993, nº 62-63, p. 153-167

DÍAZ, F. Cognición situada y estrategias para el aprendizaje significativo. Revista Electrónica de Investigación Educativa, 2003, Vol. 5, nº 2, p. 105-117

FERNÁNDEZ, T. Mapas conceptuales y diagramas uve: dos estrategias en la enseñanza-aprendizaje de la historia. Comunicación, Lenguaje y Educación, 1992, $\mathrm{n}^{\circ}$ 16, p.7-24.

FERNÁNDEZ, M.L. El mapa conceptual, un recurso didáctico para la enseñanza con TIC orientado a la adquisición de aprendizajes significativos. Murcia: TICEMUR y Universidad de Murcia, 2005, p. 466-472.

GARCÍA, M., GONZÁLEZ, R., GONZÁLEZ, R. M., RODRÍGUEZ, S., VALLE, A. y VIEIRO, P. Estrategias y técnicas de estudio. Cómo aprender a estudiar estratégicamente. Madrid: Pearson Education, 2005.

LARA, J. y LARA, L. Recursos para un aprendizaje significativo. Ceuta: Ediciones Universidad de Salamanca, 2004.

MAQUEDA, C. y MARTÍNEZ, E. La Historia y las ciencias humanas. Didáctica técnicas de estudio. Madrid: Istmo, 1989.

ROWNTREE, D. Aprende a estudiar. Introducción programada a unas mejores técnicas de estudio. Empresa editorial HERDER, Barcelona, 1976.

SALAS, M., Técnicas de estudio para Secundaria y Universidad. Madrid: Alianza, 2000.

SEBASTIÁ, R. Investigación e innovación en didáctica de las Ciencias Sociales: Historia. Alicante: Ramón Torres Gosálvez, 2009. 
PALLARÉS, E. Didáctica del estudio y de las técnicas de trabajo intelectual. Bilbao: Ediciones Mensajero, 1987.

PLUCKROSE, H. Enseñanza y aprendizaje de la historia. Madrid: Ediciones Morata y Ministerio de Educación y Cultura, 2000.

(c) Copyright Pilar Guirao Rubio, 2013.

(C) Copyright GeoGraphos, 2013.

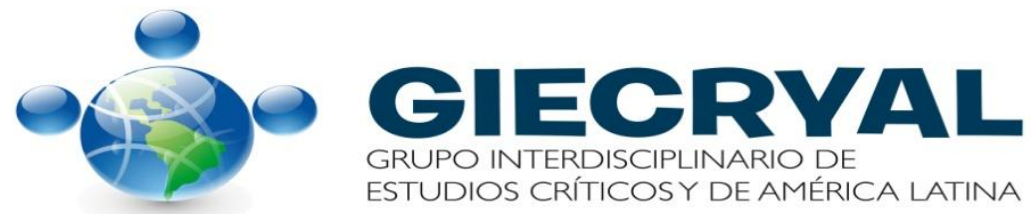

